\title{
Involvement of epithelial-to-mesenchymal transition and associated transforming growth factor- $\beta /$ Smad signaling in paraquat-induced pulmonary fibrosis
}

\author{
YING-YING HAN $^{1,3^{*}}$, PENG SHEN ${ }^{2,3^{*}}$ and WEN-XIU CHANG ${ }^{1}$ \\ Departments of ${ }^{1}$ Nephrology and ${ }^{2}$ Emergency Medicine, Tianjin First Center Hospital, Tianjin 300192; \\ ${ }^{3}$ Graduate School, Tianjin University of Traditional Chinese Medicine, Tianjin 300193, P.R. China
}

Received December 30, 2014; Accepted September 25, 2015

DOI: $10.3892 / \mathrm{mmr} .2015 .4454$

\begin{abstract}
Paraquat (PQ) is a highly toxic herbicide which is able to induce pulmonary fibrosis in humans and animals. The epithelial-to-mesenchymal transition (EMT) was demonstrated to be an important factor in pulmonary fibrosis. However, it has remained elusive whether PQ induces pulmonary fibrosis via EMT, which was therefore investigated in the present study. In addition, the underlying mechanisms of PQ-induced EMT were examined in vitro. Hematoxylin and eosin staining of rat lung tissues demonstrated that PQ induced pulmonary fibrosis in vivo. Western blot analysis then revealed that the expression of epithelial cell marker E-cadherin was significantly decreased, while the expression of mesenchymal markers $\alpha$-smooth-muscle actin and vimentin was significantly increased in rat lung tissues and A549 cells following PQ treatment. Transforming growth factor (TGF)- $\beta /$ Smad signaling was also induced by PQ as evidenced by increased expression of TGF- $\beta 1$ and Smad2. However, PQ-induced EMT in A549 cells was abolished by transfection with TGF- $\beta 1$-specific small hairpin RNA. In conclusion, the present study demonstrated that PQ induced EMT in vivo and in vitro, which may be an important process in the development of PQ-induced pulmonary fibrosis. In addition, TGF- $\beta /$ Smad signaling was involved in PQ-induced EMT.
\end{abstract}

Correspondence to: Dr Peng Shen, Department of Emergency Medicine, Tianjin First Center Hospital, 24 Fukang Road, Nankai, Tianjin 300192, P.R. China

E-mail: shenpeng008@126.com

Professor Wen-Xiu Chang, Department of Nephrology, Tianjin First Center Hospital, 24 Fukang Road, Nankai, Tianjin 300192, P.R. China

E-mail: changwx73@yeah.net

*Contributed equally

Keywords: paraquat, pulmonary fibrosis, epithelial-to-mesenchymal transition, transforming growth factor- $\beta /$ Smad signaling

\section{Introduction}

Paraquat (PQ) is a widely used non-selective herbicide. It is highly toxic upon uptake into the human body, with the lungs being its major target organ (1-3). Paraquat poisoning has a high mortality rate due to the lack of effective treatments and antidotes.

The lung is the main organ of PQ accumulation (4). PQ-induced pulmonary toxicity causes pulmonary edema, hemorrhage, interstitial inflammation and damage to the alveolar epithelium, which may progress to severe fibrosis $(5,6)$. The most common cause of mortality from PQ poisoning is respiratory failure due to pulmonary fibrosis (7).

Although PQ is known to induce pulmonary fibrosis, the pathogenic mechanism of PQ-induced pulmonary fibrosis has remained to be fully elucidated. Recent studies have demonstrated the role of the epithelial-to-mesenchymal transition (EMT) in the pathogenesis of pulmonary fibrosis (8-10). However, whether EMT occurs in PQ-induced pulmonary fibrosis has remained elusive. Therefore, the present study was designed to investigate the involvement of EMT in pulmonary fibrosis caused by paraquat. Furthermore, the participation of the transforming growth factor (TGF)- $\beta /$ Smad pathway, which is known to induce EMT and fibrosis, was examined to clarify the underlying mechanisms of PQ-induced EMT in vitro.

\section{Materials and methods}

Animal model of $P Q$-induced pulmonary fibrosis. A total of 32 adult male Sprague-Dawley rats weighing 200-250 g, aged 6-8 weeks were provided by the Laboratory Animal Center, Academy of Military Medical Sciences (Beijing, China). The rats were housed in individual cages with free access to food and fresh water, and under conditions of a $12 \mathrm{~h} / 12 \mathrm{~h}$ light/dark cycle and a controlled temperature $\left(22-24^{\circ} \mathrm{C}\right)$. The experimental animal protocol of the present study was approved by the Ethics Committee of Tianjin First Center Hospital (Tianjin, China) and followed the national and institutional guidelines for animal experiments. Paraquat was purchased from Sigma-Aldrich (St. Louis, MO, USA). The rats in the control group $(n=8)$ were administered with saline. Rats in the treatment group $(n=24)$ were intraperitoneally injected with PQ at 


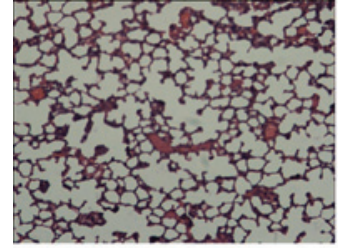

control

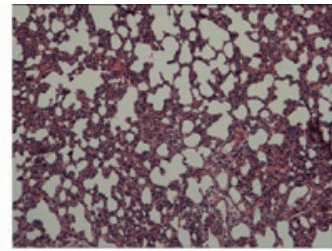

7 days

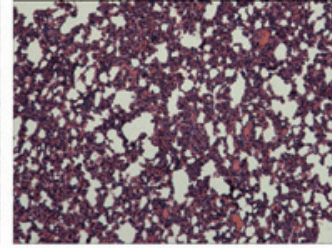

14 days

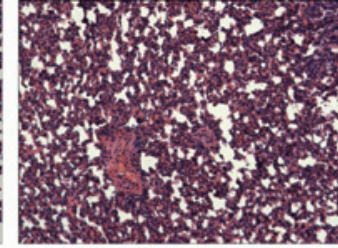

21 days

Figure 1. Hematoxylin and eosin staining of rat lung tissues $(n=3)$ following treatment with paraquat (magnification, $x 200)$.

a dose of $15 \mathrm{mg} / \mathrm{kg}$ per rat. On days 7, 14 and 21 following PQ treatment, the rats were anesthetized by intraperitoneal injection of pentobarbital $(20 \mathrm{mg} / \mathrm{kg})$. The lungs were excised and immediately frozen in liquid nitrogen.

Cell culture. The A549 lung cancer cell line were purchased from the American Type Culture Collection (Manassas, VA, USA). Cells were cultured in Dulbecco's modified Eagle's medium (Invitrogen; Thermo Fisher Scientific, Waltham, MA, USA) containing $10 \%$ fetal bovine serum (Invitrogen) at $37^{\circ} \mathrm{C}$ in a humidified atmosphere with $5 \% \mathrm{CO}_{2}$. PQ was diluted with saline solution to obtain various final concentrations $(5,10,25$, 50 and $100 \mu \mathrm{M}$ ), with which A549 cells were treated for $24 \mathrm{~h}$.

Transfection. To knockdown the expression of TGF- $\beta 1$, small hairpin (sh)RNA specific for TGF- $\beta 1$ was constructed and transfected into A549 cells using Lipofectamine ${ }^{\mathrm{TM}} 2000$ (Invitrogen) according to the manufacturer's instructions. The sequences of shRNAwereasfollows:Sense5'-CACCCAGCACGTGGAGCTG TACCAGAAATTTCAAGAGAATTTCTGGTACAGCT CCACGTGCTG T T T T T TG-3' and antisense 5'-GATCCAAAAAACAGCACGTGGAGCTGTACCAGAAA TTCTCTTGAAAGGGCTGGTACAG CTCCACGTGCTG-3'. The shRNA were synthesized by GenePharma Co., Ltd. (Shanghai, China). Prior to transfection, cells were seeded into six-well plates and allowed to attach for $24 \mathrm{~h}$. $5 \mu \mathrm{l}$ Lipofectamine $^{\mathrm{TM}} 2000$ and $4 \mu \mathrm{g}$ TGF- $\beta 1$-specific shRNA were diluted in $250 \mu$ l Opti-Mimimum Essential Medium I (Invitrogen) each. The solutions were mixed and incubated at room temperature for $20 \mathrm{~min}$ to form lipid-DNA complexes. Cells were incubated with the lipid-DNA complexes at $37^{\circ} \mathrm{C}$ for $6 \mathrm{~h}$. Subsequently, the supernatant was replaced with fresh medium and cells were maintained in culture for $24 \mathrm{~h}$.

Hematoxylin and eosin (HE) staining. The left lungs were fixed in $10 \%$ paraformaldehyde solution (Beijing Dinguo Chansheng Biotechnology Co., Ltd., Beijing China) de-hydrated and then embedded in paraffin. $4-\mu \mathrm{m}$ sections were cut and mounted on slides. To remove the paraffin, the slides were immersed in xylene (Guangzhou Xinchenghuagong, Inc., Guangzhou, China) and a graded series of ethanol (Guangzhou Xinchenghuagong, Inc.). Subsequently, the tissue samples were stained with HE (Maixin, Fuzhou, China). The sections were observed and images were captured using a light microscope (E200; Nikon, Tokyo, Japan).

Western blot analysis. Total protein was extracted from the rat lung tissues and A549 cells using a total protein extraction kit (cat. no. E211-02; Vazyme, Inc., Nanjing, China). Protein concentrations were determined using a bicinchoninic acid kit (cat. no. P0010; Beyotime Institute of Biotechnology, Haimen, China). Protein samples $(50 \mu \mathrm{g})$ were separated by $10 \%$ SDS-PAGE and then transferred onto a nitrocellulose membrane (EMD Millipore Corp., Billerica, MA, USA). The nitrocellulose membrane was blocked with $3 \%$ bovine serum albumin (Amresco Inc., Solon, OH, USA) in Tris-buffered saline overnight at $4^{\circ} \mathrm{C}$. After washing with phosphate-buffered saline, the membrane was incubated with the following primary antibodies: rabbit polyclonal anti-E-cadherin (cat. no. sc-7870; 1:800), mouse monoclonal anti-vimentin (cat. no. sc-373717; 1:400), rabbit polyclonal anti-TGF- $\beta 1$ (cat. no. sc-146; 1:400), mouse monoclonal anti-Smad2 (cat. no. sc-101153; 1:200), all from Santa Cruz Biotechnology, Inc. (Dallas, TX, USA), mouse monoclonal anti- $\alpha$-smooth muscle actin (cat. no. BM0002; 1:500) or rabbit polyclonal anti-GAPDH (cat. no. BA2913; 1:2,000), both from Boster Biological Technology Ltd., (Wuhan, China), overnight at $4^{\circ} \mathrm{C}$. The membrane was then incubated with the horseradish peroxidase (HRP)-labeled secondary antibody [goat anti-mouse immunoglobulin (Ig)G-HRP; sc-2005; 1:4,000) or goat anti-rabbit IgG-HRP (cat. no. sc-2004; 1:4,000; Santa Cruz Biotechnology, Inc.) for $2 \mathrm{~h}$ at room temperature. The immunoreactive proteins were detected using an enhanced chemiluminescence kit (cat. no. 32209; Pierce Biotechnolgy, Inc., Rockford, IL, USA). GAPDH was used as a loading control. Images of the blots were captured using a ScanJet 4C Flatbed Scanner (Hewlett-Packard, Palo Alto, CA, USA). Densitometric quantification was performed using Image-Pro Plus software (version 6.0; Media Cybernetics, Inc., Rockville, MD, USA).

Statistical analysis. Values are expressed as the mean \pm standard deviation. Two-tailed Student's t-test was used to analyze differences between two groups. SPSS 19.0 statistical software was used (IBM SPSS, Armonk, NY, USA). Data are representative of at least three independent experiments. $\mathrm{P}<0.05$ was considered to indicate a statistically significant difference between values.

\section{Results}

$P Q$ induces pulmonary fibrosis in rats. In order to identify PQ-induced pulmonary fibrosis, HE staining of lung tissues from PQ-treated rats was performed. As shown in Fig. 1, the lung structure in PQ-treated animals was distorted with severe epithelial degeneration, alveolar disruption, inflammatory cell infiltration and fibrotic invasion at day 7 following PQ treatment, which was further aggravated with increasing time until the end of the experiment on day 21 . 

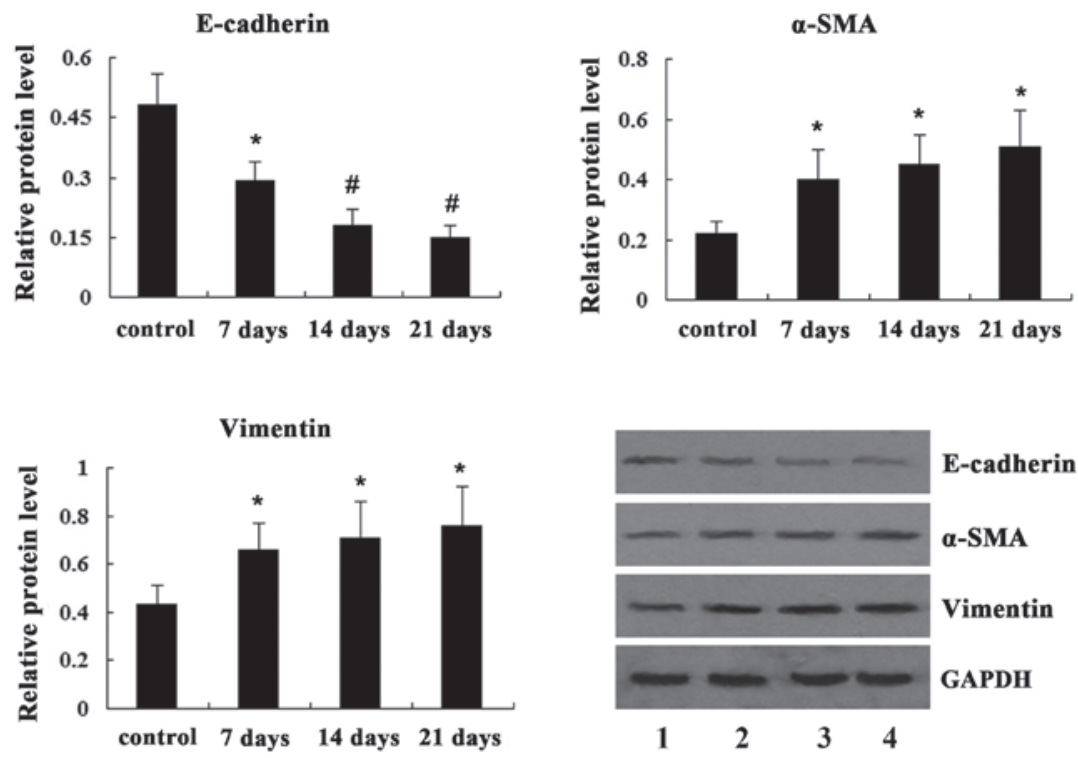

Figure 2. Effects of paraquat treatment on the expression of epithelial-to-mesenchymal transition markers in rat lung tissues. Lanes: 1, control group; 2, 7-day group; 3, 14-day group; 4, 21-day group. Values are expressed as the mean \pm standard deviation $(n=3){ }^{*} \mathrm{P}<0.05 ;{ }^{*} \mathrm{P}<0.01$ vs. control group. SMA, smooth muscle actin.
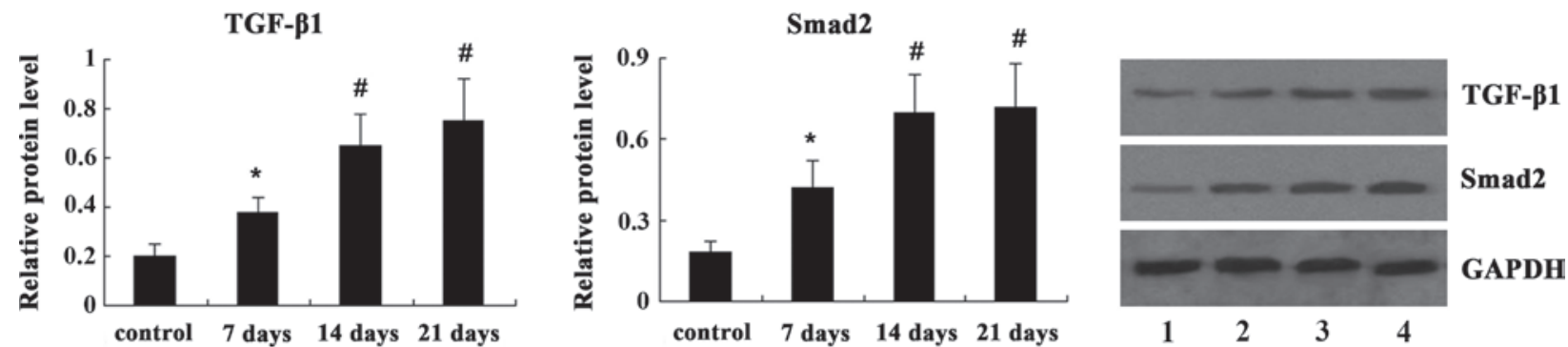

Figure 3. Effects of paraquat treatment on TGF- $/$ /Smad pathway in rat lung tissues. Lanes: 1, control group; 2, 7-day group; 3,14-day group; 4, 21-day group. Values are expressed as the mean \pm standard deviation $(\mathrm{n}=3)$. ${ }^{*} \mathrm{P}<0.05 ;{ }^{*} \mathrm{P}<0.01$ vs. control group. TGF, transforming growth factor.
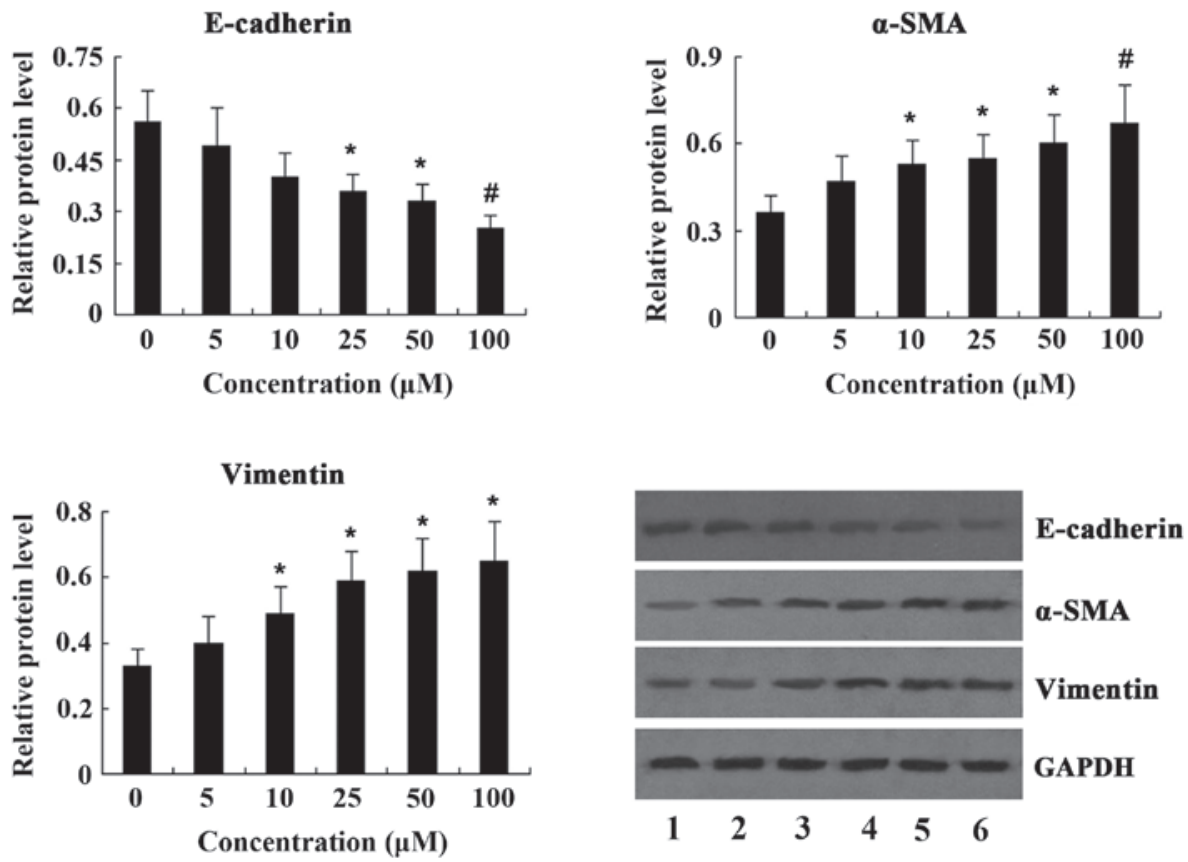

Figure 4. Effects of PQ treatment on the expression of epithelial-to-mesenchymal transition markers in A549 cells. Lanes 1-6 represent cells treated with 0, 5, 10, 25, 50 and $100 \mu \mathrm{M} \mathrm{PQ}$, respectively. Values are expressed as the mean \pm standard deviation $(\mathrm{n}=4)$. ${ }^{*} \mathrm{P}<0.05$ and ${ }^{\#} \mathrm{P}<0.01$ vs. $0 \mu \mathrm{M}$ group. $\mathrm{PQ}$, paraquat; SMA, smooth-muscle actin. 


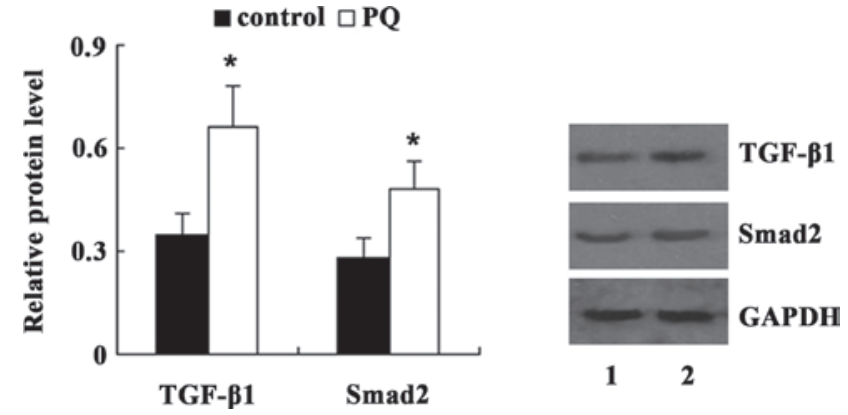

Figure 5. Effects of PQ treatment on the TGF- $\beta /$ Smad pathway in A549 cells. Lanes: 1, control group; 2, PQ group. Values are expressed as the mean \pm standard deviation ( $\mathrm{n}=4)$. $\mathrm{P}<0.05$ vs. control group. $\mathrm{PQ}$, paraquat; TGF, transforming growth factor.
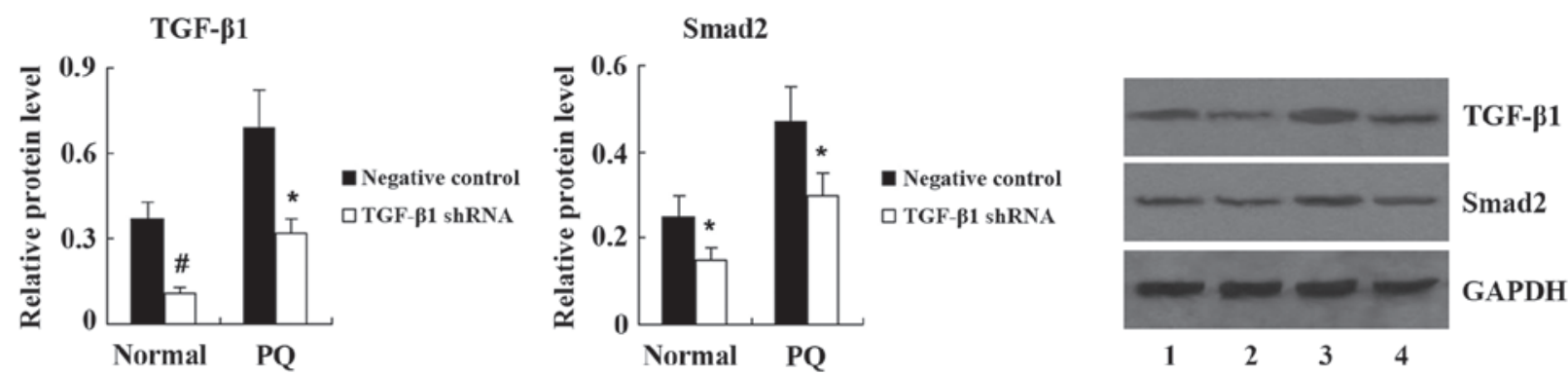

Figure 6. Expression of TGF- $\beta 1$ and Smad2 in normal and PQ-treated A549 cells following transfection with TGF- $\beta 1$ shRNA. Lanes: 1, PQ-untreated negative control group; 2 , PQ-untreated TGF- $\beta 1$ shRNA group; $3, \mathrm{PQ}+$ negative control group; 4 , PQ + TGF- $\beta 1$ shRNA group. Values are expressed as the mean \pm standard deviation $(n=4) .{ }^{*} \mathrm{P}<0.05$ and ${ }^{~} \mathrm{P}<0.01$ vs. negative control group. $\mathrm{PQ}$, paraquat; Normal, $\mathrm{PQ}$-untreated; shRNA, small hairpin $\mathrm{RNA}$; TGF, transforming growth factor.
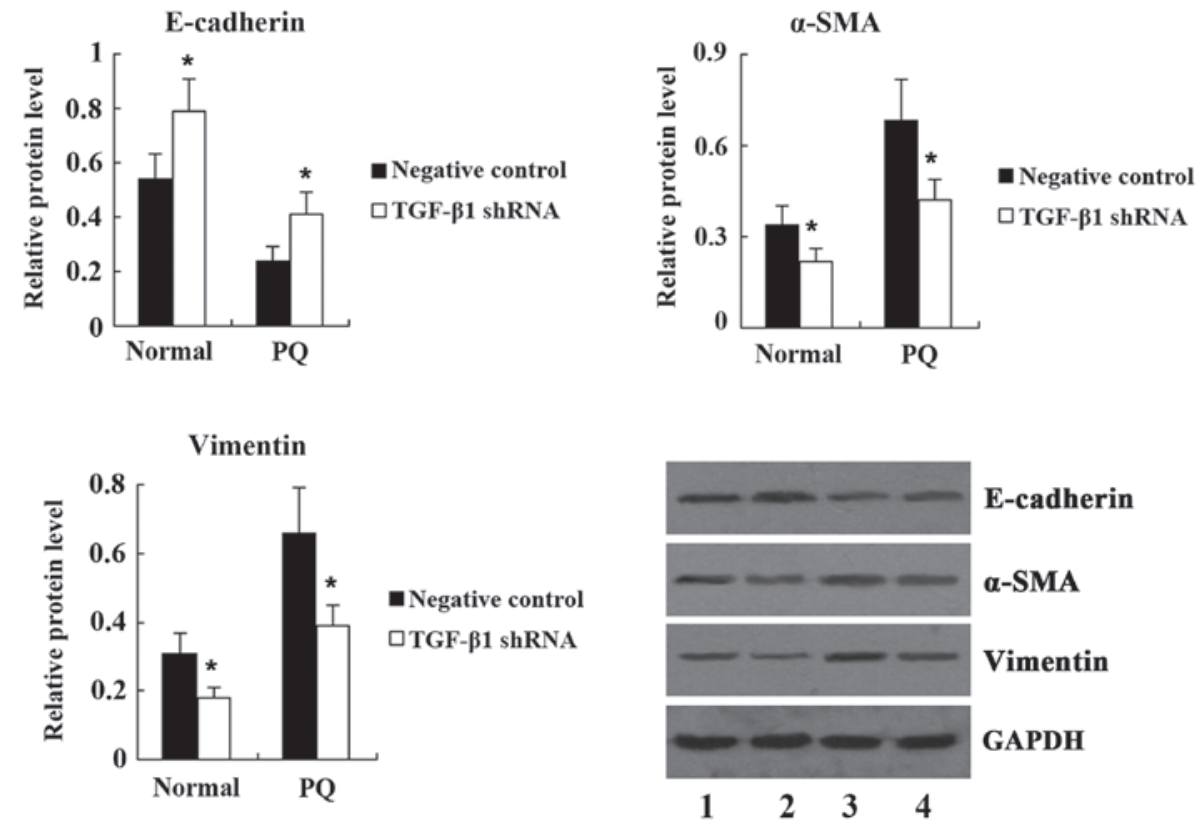

Figure 7. Expression of epithelial-to-mesenchymal transition markers in normal and PQ-treated A549 cells following transfection with TGF- $\beta 1$ shRNA. Lanes: 1 , PQ-untreated negative control group; 2 , PQ-untreated TGF- $\beta 1$ shRNA group; 3 , PQ + negative control group; 4 , PQ + TGF- $\beta 1$ shRNA group. Values are expressed as the mean \pm standard deviation $(n=4)$. "P<0.05 vs. negative control group. $\mathrm{PQ}$, paraquat; Normal, $\mathrm{PQ}$-untreated; shRNA, small hairpin $\mathrm{RNA}$; TGF, transforming growth factor; SMA, smooth-muscle actin.

$P Q$ treatment enhances the expression of EMT markers in rat lung tissues. To examine the effects of PQ treatment on the EMT in rat lung tissues, the expression of molecular EMT markers, including E-cadherin, $\alpha$-SMA and vimentin, was detected by western blot analysis. As shown in Fig. 2, the epithelial-cell marker E-cadherin was decreased following PQ treatment as compared with that in the control group, and progressively decreased until the end of the experiment on day 21. By contrast, from day 7 onwards, an increase in the expression of mesenchymal cell markers $\alpha$-SMA and vimentin was observed. 
$P Q$ treatment upregulates TGF- $\beta /$ Smad signaling in rat lung tissues. Next, the present study examined the effects of PQ treatment on the TGF- $\beta /$ Smad signaling pathway in rat lung tissues. As shown in Fig. 3, western blot analysis indicated that the expression of TGF- $\beta 1$ and Smad 2 was significantly increased on day 7 following PQ treatment $(\mathrm{P}<0.05)$ and was further increased on days 14 and $21(\mathrm{P}<0.01)$.

$P Q$ treatment enhances the expression of EMT markers in vitro. To investigate the induction of the EMT by PQ in vitro, A549 lung cancer cells were incubated with various concentrations of PQ $(5,10,25,50$ and $100 \mu \mathrm{M})$ for $24 \mathrm{~h}$ and the expression of EMT markers was determined by western blot analysis. The results revealed that treatment of A549 cells with PQ resulted in a dose-dependent decrease of E-cadherin expression, while the expression of $\alpha$-SMA and vimentin was significantly increased in a dose-dependent manner following PQ treatment (Fig. 4).

TGF- $\beta /$ Smad pathway mediates the $P Q$-induced EMT in A549 cells. To clarify the underlying mechanisms of PQ-induced EMT in A549 cells, the present study examined the expression of TGF- $\beta 1$ and Smad 2 in A549 cells following treatment with $100 \mu \mathrm{M}$ PQ for $24 \mathrm{~h}$. Western blot analysis demonstrated that compared with the control, the expression of TGF- $\beta 1$ and Smad2 was significantly increased in A549 cells treated with PQ (Fig. 5). Next, TGF- $\beta 1$ shRNA was transfected into A549 cells to knockdown TGF- $\beta 1$ expression. Western blot analysis showed that the expression of TGF- $\beta 1$ and Smad2 was significantly decreased in PQ-untreated A549 cells following TGF- $\beta 1$ shRNA transfection. PQ-induced upregulation of TGF- $\beta 1$ and Smad 2 was also significantly suppressed by TGF- $\beta 1$ shRNA (Fig. 6). As shown in Fig. 7, transfection with TGF- $\beta 1$ shRNA led to an increase in E-cadherin, and a decrease in $\alpha$-SMA and vimentin expression in PQ-untreated A549 cells. Furthermore, compared with the PQ group, the expression of E-cadherin was significantly increased, while the expression of $\alpha$-SMA and vimentin was significantly decreased in the PQ + TGF- $\beta 1$ shRNA group.

\section{Discussion}

Paraquat is a highly toxic herbicide which induces pulmonary fibrosis in humans and animals. In the present study, adult male Sprague-Dawley rats were treated by intraperitoneal injection with PQ and the time-dependent development of pulmonary fibrosis was confirmed by HE staining at days 7, 14 and 21. Next, the present study aimed to elucidate the mechanisms involved in PQ-induced in vivo and in vitro.

Lung tissues from patients with pulmonary fibrosis are known to contain myofibroblasts (11-14), which are responsible for the deposition of collagen and other extracellular matrix components during the development and progression of pulmonary fibrosis (15). It has been suggested that myofibroblasts are derived from at least three sources (16-19): Proliferation and activation of resident tissue fibroblasts, transition of alveolar epithelial cells into mesenchymal cells and differentiation of circulating bone marrow-derived progenitor cells. An accumulating number of studies supported the notion that EMT transition has a central role in pulmonary fibrosis (8-10).

EMT is a process during which epithelial cells lose their epithelial cell characteristics and acquire mesenchymal characteristics. During the EMT, the expression of the epithelial marker E-cadherin is lost, while the expression of mesenchymal markers, including $\alpha$-SMA, vimentin and matrix metalloproteinase, is increased, leading to the loss of cell-cell contacts, cytoskeletal rearrangement, increased cell-migratory behavior and excess extracellular matrix production (20). The present study investigated the involvement of the EMT in PQ-induced pulmonary fibrosis. The in vivo study showed that the expression of epithelial marker E-cadherin was significantly decreased, while the expression of mesenchymal markers $\alpha$-SMA and vimentin was significantly increased in the lung tissues of PQ-treated rats. These results suggested that the EMT was involved in PQ-induced pulmonary fibrosis in rats. Next, the present study investigated the effects of PQ on EMT markers in vitro. Western blot analysis demonstrated a decrease of E-cadherin and an increase of $\alpha$-SMA and vimentin in PQ-treated A549 cells in a dose-dependent manner. Therefore, the in vitro study confirmed that PQ induced EMT in lung epithelial cells.

TGF- $\beta 1$ is a pivotal mediator of fibrosis (21-23) and the TGF- $\beta 1$ signal is transduced through the activation of its downstream effectors, the Smad proteins. TGF- $\beta /$ Smad signaling induces EMT and fibrosis in a variety of organs (24-26). It has been demonstrated that TGF- $\beta 1$ was able to induce alveolar epithelial cells to undergo EMT in vivo and in vitro via Smad2 activation (27). The in vivo experiment of the present study revealed that the expression of TGF- $\beta 1$ and Smad 2 was increased in the rat model of PQ-induced pulmonary fibrosis. Furthermore, an in vitro experiment was performed to clarify whether TGF- $\beta /$ Smad signaling was involved in PQ-induced EMT in A549 cells. The results demonstrated that TGF- $\beta / \mathrm{Smad}$ signaling was activated and the EMT was induced in PQ-treated A549 cells; however, these effects were inhibited when PQ-treated A549 cells were transfected with TGF- $\beta 1$ shRNA. Therefore, TGF- $\beta$ /Smad signaling was confirmed to be involved in the PQ-induced EMT in A549 cells.

In conclusion, the present study provided the underlying molecular mechanism of PQ-induced pulmonary fibrosis. It was demonstrated that PQ induced EMT in vivo and in vitro, and the EMT was indicated to be an important process in the development of PQ-induced pulmonary fibrosis. In addition, TGF- $\beta /$ Smad signaling was demonstrated to be involved in PQ-induced EMT.

\section{Acknowledgements}

The present study was supported by the Science and Technology Foundation of Tianjin Municipal Health Bureau (no. 2013KY06).

\section{References}

1. Lee SK, Ameno K, In SW, Yang JY, Kim KU, Koo KS, Yoo YC, Ameno $S$ and Ijiri I: Levels of paraquat in fatal intoxications. Int J Legal Med 112: 198-200, 1999.

2. Lin JL, Lin-Tan DT, Chen KH, Huang WH, Hsu CW, Hsu HH and Yen TH: Improved survival in severe paraquat poisoning with repeated pulse therapy of cyclophosphamide and steroids. Intensive Care Med 37: 1006-1013, 2011. 
3. Wang RL, Tang X, Wu X, Xu R, Yu KL and Xu K: The relationship between HIF-1 $\alpha$ expression and the early lung fibrosis in rats with acute paraquat poisoning. Chinese Journal of Industrial Hygiene and Occupational Diseases 30: 273-277, 2012 (In Chinese).

4. Dinis-Oliveira RJ, Duarte JA, Sánchez-Navarro A, Remião F, Bastos ML and Carvalho F: Paraquat poisonings: Mechanisms of lung toxicity, clinical features and treatment. Crit Rev Toxicol 38: 13-71, 2008.

5. Venkatesan N: Pulmonary protective effects of curcumin against paraquat toxicity. Life Sci 66: PL21-PL28, 2000.

6. Tomita M, Okuyama T, Katsuyama H, Miura Y, Nishimura Y, Hidaka K, Otsuki T and Ishikawa T: Mouse model of paraquat-poisoned lungs and its gene expression profile. Toxicology 231: 200-209, 2007.

7. Hagiwara S, Iwasaka H, Matsumoto $\mathrm{S}$ and Noguchi T: An antisense oligonucleotide to HSP47 inhibits paraquat-induced pulmonary fibrosis in rats. Toxicology 236: 199-207, 2007.

8. Willis BC, Liebler JM, Luby-Phelps K, Nicholson AG Crandall ED, du Bois RM and Borok Z: Induction of epithelial-mesenchymal transition in alveolar epithelial cells by transforming growth factor-beta1: Potential role in idiopathic pulmonary fibrosis. Am J Pathol 166: 1321-1332, 2005.

9. Kim KK, Kugler MC, Wolters PJ, Robillard L, Galvez MG, Brumwell AN, Sheppard D and Chapman HA: Alveolar epithelial cell mesenchymal transition develops in vivo during pulmonary fibrosis and is regulated by the extracellular matrix. Proc Nat Acad Sci USA 103: 13180-13185, 2006

10. Kim KK, Wei Y, Szekeres C, Kugler MC, Wolters PJ, Hill ML, Frank JA, Brumwell AN, Wheeler SE, Kreidberg JA and Chapman HA: Epithelial cell alpha3betal integrin links beta-catenin and Smad signaling to promote myofibroblast formation and pulmonary fibrosis. J Clin Invest 119: 213-224, 2009.

11. Adler KB,Low RB, Leslie KO, Mitchell J and Evans JN: Contractile cells in normal and fibrotic lung. Lab Invest 60: 473-485, 1989.

12. Mitchell J, Woodcock-Mitchell J, Reynolds S, Low R, Leslie K, Adler K, Gabbiani G and Skalli O: Alpha-smooth muscle actin in parenchymal cells of bleomycin-injured rat lung. Lab Invest 60: 643-650, 1989
13. Kuhn C and McDonald JA: The roles of the myofibroblast in idiopathic pulmonary fibrosis. Ultrastructural and immunohistochemical features of sites of active extracellular matrix synthesis. Am J Pathol 138: 1257-1265, 1991.

14. Pache JC, Christakos PG, Gannon DE, Mitchell JJ, Low RB and Leslie KO: Myofibroblasts in diffuse alveolar damage of the lung. Mod Pathol 11: 1064-1070, 1998.

15. Phan SH: The myofibroblast in pulmonary fibrosis. Chest 122 (Suppl 6): S286-S289, 2002.

16. Epperly MW, Guo H, Gretton JE and Greenberger JS: Bone marrow origin of myofibroblasts in irradiation pulmonary fibrosis. Am J Respir Cell Mol Biol 29: 213-224, 2003.

17. Willis BC, duBois RM and Borok Z: Epithelial origin of myofibroblasts during fibrosis in the lung. Proc Am Thorac Soc 3: 377-382, 2006

18. Scotton CJ and Chambers RC: Molecular targets in pulmonary fibrosis: The myofibroblast in focus. Chest 132: 1311-1321, 2007.

19. Kasai H, Allen JT, Mason RM, Kamimura T and Zhang Z: TGF-beta1 induces human alveolar epithelial to mesenchymal cell transition (EMT). Respir Res 6: 56, 2005

20. Kalluri R and Weinberg RA: The basics of epithelial-mesenchymal transition. J Clin Invest 119: 1420-1428, 2009.

21. Leask A and Abraham DJ: TGF-beta signaling and the fibrotic response. FASEB J 18: 816-827, 2004.

22. Steen V: Targeted therapy for systemic sclerosis. Autoimmun Rev 5: 122-124, 2006

23. Bergeron A, Soler P, Kambouchner M, Loiseau P, Milleron B, Valeyre D, Hance AJ and Tazi A: Cytokine profiles in idiopathic pulmonary fibrosis suggest an important role for TGF-beta and IL-10. Eur Respir J 22: 69-76, 2003.

24. Thiery JP and Sleeman JP: Complex networks orchestrate epithelial-mesenchymal transitions. Nat Rev Mol Cell Biol 7: 131-142, 2006.

25. Chapman HA: Epithelial-mesenchymal interactions in pulmonary fibrosis. Annu Rev Physiol 73: 413-435, 2011.

26. Xu J, Lamouille S and Derynck R: TGF-beta-induced epithelial to mesenchymal transition. Cell Res 19: 156-172, 2009.

27. Willis BC and Borok Z: TGF-beta-induced EMT: Mechanisms and implications for fibrotic lung disease. Am J Physiol Lung Cell Mol Physiol 293: L525-L534, 2007. 